\title{
DESIGN AND EVALUATION OF MECHANICAL PICKING HEADS FOR CITRUS FRUITS HARVESTING
}

\author{
HAMAM, A. S., M. E. EL-IRAQI, Y. SHARIBIM AND T. R. AWAIS
}

\author{
1. Agric. Eng. Res. Inst., ARC, Dokki, Giza. Egypt.
}

(Manuscript received 12 April 2011)

\begin{abstract}
In this study, two prototypes of rotary cone harvesting and harvesting electrical scissors heads were designed, fabricated and evaluated to reduce the required number of manual picker and maximize its productivity that reduce harvesting costs. The rotary harvesting head was evaluated under four types of rotary cone and four cone rotational speeds of 300, 450, 600, and $750 \mathrm{rpm}$ for harvesting of Washingtonia and Valencia orange fruits compared with traditional harvesting method. While, the electrical scissors harvesting head was evaluated using five different skill labors for harvesting of Washingtonia, Valencia, Mandarin and Lemon citrus fruits compared with traditional harvesting method. The important obtained results could be concluded as follows:
\end{abstract}

- Using harvesting rotary cone type IV (metal cone provided with rubber inner surface and without upper edge) at cone rotary speed of $600 \mathrm{rpm}$ increased the labor productivity from 0.111 and 0.084 ton/h using traditional harvesting method to 0.208 and 0.154 ton/h for harvesting Washingtonia and Valencia orange fruits, respectively and maintain the optimum fruit quality by increasing the percentage of fruit with calyx-Grade I (65.96$73.01 \%)$ and decreasing the percentage of damaged fruit Grade IV (1.20-4.31\%).

- Using electrical scissors head increased the labor productivity from $0.111,0.084,0.053$ and 0.013 ton/h using traditional harvesting method to $0.153,0.129,0.084$ and 0.016 ton/h with maintain the higher percentages of grade I $(<0.5 \mathrm{~cm}$ twig length) of $43.35,51.15,51.78$ and $53.00 \%$ and the lower damaged fruit percentages of $6.71,4.55,3.55$ and $1.97 \%$ for harvesting Washingtonia and Valencia orange, Mandarin and Lemon fruits, respectively.

- Using mechanical citrus harvesting methods saving the harvesting cost by about 25.85 - $59.58 \%$ for harvesting Washingtonia orange fruits and by about 53.00 - $67.99 \%$ for harvesting Valencia orange fruits compared with traditional citrus harvesting methods.

- The authors recommended to locally fabricate and use the rotary cone and electrical scissors harvesting heads to increase the labor productivity and the rate of fresh market exporting, reduce the harvesting cost and consequently increase the farmer benefit and national income. In addition to decrease the hazards of platforms and lifting methods using traditional methods during harvesting citrus fruits. 


\section{INTRODUCTION}

Egypt stands among the largest citrus producing countries in the world and occupies the fourth rank in production amongst the Mediterranean basin countries. Egyptian citrus has advantages in terms of yield and fruit quality, early ripening, relative low labor cost and close to international importing markets, consequently, this creates a unique situation for Egyptian and exported quantities have been generally increasing. Citrus are considered the most important fruit corps being cultivated in Egypt. It represents about $31.6 \%$ of the total cultivated fruit area $(359,703$ fed). However the total citrus production in Egypt is about $40.1 \%$ of the total fruit production $(7.192,715$ million tons) the volume of fresh citrus fruit exports about $21.8 \%$ of the total citrus fruit production $(630,000$ tons), the orange represents $62 \%$ of the citrus fruit followed by mandarin $27.5 \%$ and limes $10.9 \%$ of the total citrus area in Egypt (Horticultural institute brochure No. 850, 2003).

Manual citrus harvesting has been used for many years. However, due to labor shortages and the increasing cost of harvesting operations, the use of mechanical harvesting systems has been increasing in the last several years. At the same time, significant efforts have been devoted to improve productivity and mechanize the harvesting of the Egyptian citrus crop. Abo EI-Kheir, 1993, designed and developed a small hand - held harvester machine arm- to be used in harvesting lime fruits. An arc shape cutting blade was used to control catching and cutting fruit peduncle. Evaluation of the harvester performance indicated that, the percentage of picked fruits to total number of fruits ranged from $90 \%$ to $100 \%$, but the effect of utilizing this arm on the worker, productivity was not mentioned. Also, Abou Elmagd et. al. (2002) designed, fabricated and tested an orange detacher prototype in picking Washingtonia orange variety. Their results indicated that the minimum fruit detachment time was obtained at a friction coefficient of about 0.81 for Washingtonia variety. The cone rotating speed of $680 \mathrm{rpm}$ gave the best results for the shortest remaining twig height of $0.88 \mathrm{~mm}$ and optimum cone angle of $52^{\circ}$. The developed picking method was found superior when compared to the manual traditional picking methods. Since, it accomplished about (87.9\%) of fruits grade (I), low percentages of fruit, with twig (9\%), and fruits without calyx (3\%).

Futch et. al. (2004) reported that during the last 40 years, significant efforts have been devoted to improve productivity and mechanize the harvesting of the Florida citrus crop. Initial work focused on ways to improve the hand harvesting operation by providing harvesting aids to improve worker productivity. Through these 
studies, it was determined that the hand harvesters spent at least 25 percent of their time in activities that were not directly related to fruit removal from the tree.

Burks et. al. (2005) cleared that automated solutions for fresh market fruit and vegetable harvesting have been studied by numerous researchers around the world during the past several decades such as Seamount and Opitz (1973a), Sumner (1978), Ben-Tal (1983), O'brien et. al. (1986), Grand d'Esnon et. al. (1987), Herrell et. al. (1990) and Whitney et. al. (1996). However, very few developments have been adopted and put into practice. The reasons for this lack of success arc due to technical, economic, horticultural, and producer acceptance issues. Viable solutions will require engineers and horticultural scientists who understand crop-specific biological systems and production practices, as well as the machinery, robotic, and controls issues associated with the automated production systems.

Sanders (2005) concluded that mechanical harvesting provides a significantly higher harvesting rate over manual picking. The maximum picking rate of manual pickers is $0.5 \mathrm{t} / \mathrm{h}$, whereas the picking rate of trunk shaking harvesters is $10 \mathrm{t} / \mathrm{h}$ and of canopy shakers is $25 \mathrm{t} / \mathrm{h}$. Hence, a mechanical harvester can replace 20-50 manual pickers. Manual harvesting offers the benefits of maximum fruit selection and maximum product quality, but has the disadvantages of uncertain labor availability and a relatively low picking rate. Also, he added that the harvesting of citrus fruit represents $35-45 \%$ of total production cost. Hence, an improvement in the efficiency of this one operation has a significant effect upon enterprise viability and profitability. The traditional manual harvesting method is very labor intensive, and thus expensive. Mechanical harvesting methods have been widely researched and significantly improved.

Futch and Roka, (2005) reported that two types of mechanical harvesters are being used nowadays in Florida. One of the harvesting systems is a canopy shake and catch harvester. It shakes tree canopies, causing fruit to fall onto a catch frame. Then fruit is carried through a conveyor system to the goat-like trucks. It can harvest 200 to 400 trees per hour. The second type of the harvesting system is called a trunk shake harvester, which shakes tree canopies, causing fruit to fall on the ground. Then a fruit picking crew manually collects the fruit.

A citrus fruit counting and size measurement system on a canopy shake and catch harvester was successfully developed by Chinchuluun et. al. (2009). The system was tested on a test bench as well as on a commercial canopy shake and catch harvester. The sum of areas, the number of fruit and the sum of fruit diameters were extracted using image analysis from the set of images from the test bench trial. The coefficients of determination of the sum of areas, the number of fruit and the sum of 
fruit diameters against actual fruit weight were $0.962,0.892$, and 0.963 , respectively. For the commercial harvester trial, the coefficient of determination between the number of fruit counted by image processing algorithm and human counting was 0.891 . The test bench experiments showed promising results for estimating citrus yield at harvesting, although the field trial demonstrated the need for system improvement.

\section{Problem statement}

In Egypt, during the last two decades the citrus production especially orange and mandarin are basically oriented towards the fresh market, which requires harvesting fruits without mechanical damage and assuring that fruits are harvested with its calyx for good storage and long shelf life suitable for exporting. However, the basic problems of fruit harvesting are considered and the labor intensive operation. In addition the citrus is one of the major tree crops which still being harvested by hand grasp. These concerns led to develop and mechanize the harvesting of Egyptian citrus crop. Therefore, the main goal of this study is to design, fabricate and evaluate simple fruit harvesting heads to harvest or aid in the harvesting of citrus fruit, reducing the required number of hand harvesters and improve labor productivity that will reduce harvesting costs.

\section{MATERIALS AND METHODS}

\section{1- Materials}

In this study, two designed prototypes of harvesting tools namely rotary picking head and electrical scissors harvesting head were evaluated under field harvesting conditions. The construction and the main components of both types of harvesting heads could be explained as follows:

\section{1- 1 Rotary harvesting head}

The designed rotary cone harvesting head illustrated in Figs. (1) and (2) consists mainly of:

1- Detaching mechanism: it is a metal cone $11 \mathrm{~cm}$ high and $11 \mathrm{~cm}$ diameter with cone angle of $\underline{36}^{\circ}$ (El Khawaga 1999). Four types of rotary cone (detachment mechanism) were designed and tested as the follows:

Type I: Metal cone without upper edge.

Type II: Metal cone equipped with upper edge $(1.5 \mathrm{~cm}$ height with the same upper cone diameter)

Type III: Metal cone without upper edge and covered with rubber layer on the inner cone surface.

Type IV: Metal cone with upper edge and covered with rubber layer on the inner cone surface. 
The picking fruit method by rotary picking head depends on the action of torsional shear to the supporting twig of the fruit through a small bottom (calyx) during rotating the fruit inside rotary cone.

2- Housing of the detachment mechanism: its including telescopic carrier (2-5 m), electric DC motor, battery (12 V-70Ah) and operation switches/wiring cables. In this housing the detachment unit is fixed on the shaft of electrical motor as a power source for rotary picking head, while the electrical motor is fixed at upper end of the telescopic carrier.

3- Positioning mechanism which is used to insert the picking head between the tree branches and selecting the desired mature fruits to be harvested then dropped it in the fruit receiving tube.

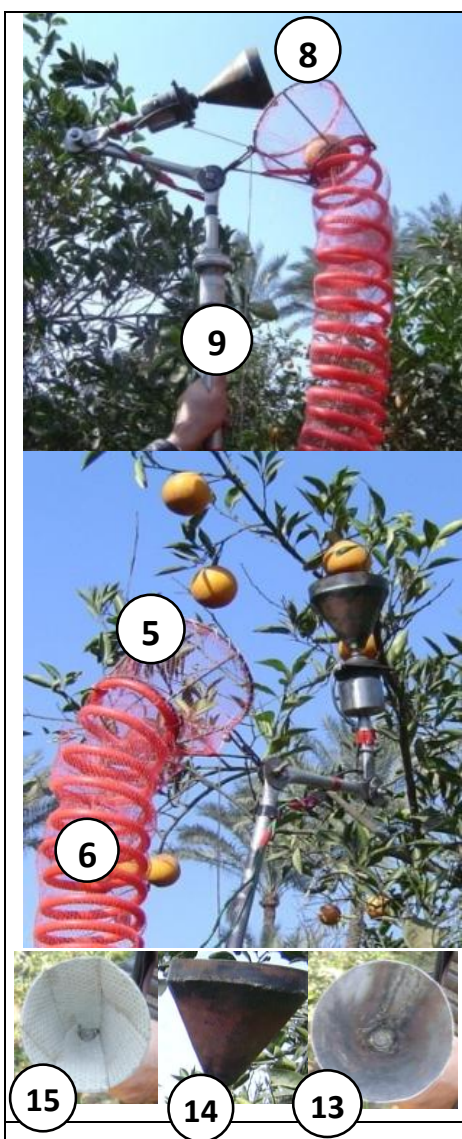

Fig. 1. The main components of rotary cone picking head.

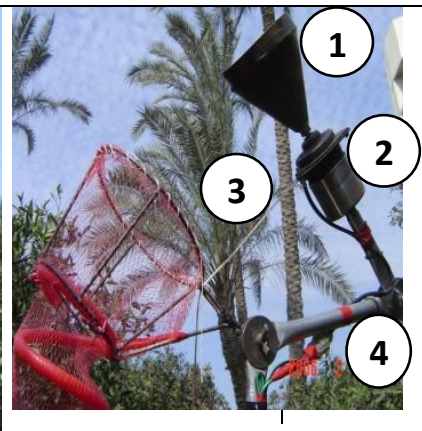

1- Picking cone

2- Dc motor

3- Positioning wire

4- Positioning mechanism

5- Fruit receiving tube

6- Fruit telescopic tube

7- Fruit collecting basket

8- Discharge position

9- Telescopic carrier

10- Positioning mechanism hand

11- Operation switch

12- DC wiring cable

13- Cone type

14- Cone type II

15- Cone type III

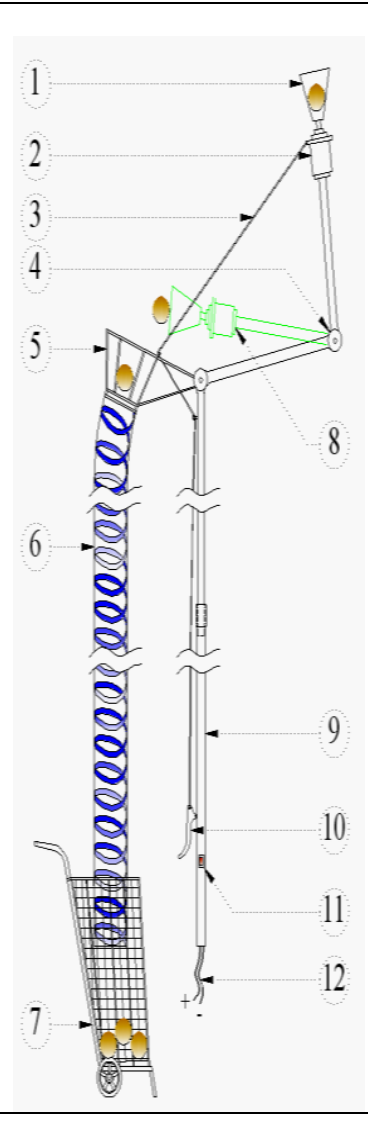

Fig. 2. Schematic diagram of rotary cone picking head.

4- Fruit receiving and collecting mechanism: it consists of: a) Fruit receiving telescopic tube which fixed on the housing mechanism to receive the detached fruit and transported it to the collecting basket. b) Fruit collecting basket which attached at the lower end of the receiving tube to collect a citrus fruits detached from citrus tree. This basket is equipped with two wheels to make it easy during moving between trees in field and also, easy to empty. 


\section{1-2 Electrical scissors harvesting head}

The construction of the electrical scissors harvesting head is shown in Figs. (3) and (4) which includes the following components:

\section{1-Cutting mechanism it consists of :}

a) Cutters (scissors) one of them is fixed and other is movable

b) Electric DC motor and battery $(12 \mathrm{~V}, 70 \mathrm{Ah})$ as the power source for the reciprocating speed of the scissors.

c) Cam, for converting the rotational speed to reciprocating speed for mobile scissor to occur the cutting action of fruit twig.

d) Wiring cable and operation switch for connecting the battery with the electrical motor and switching on/off.

e) Fixing base for electrical motor with the cam and scissors.

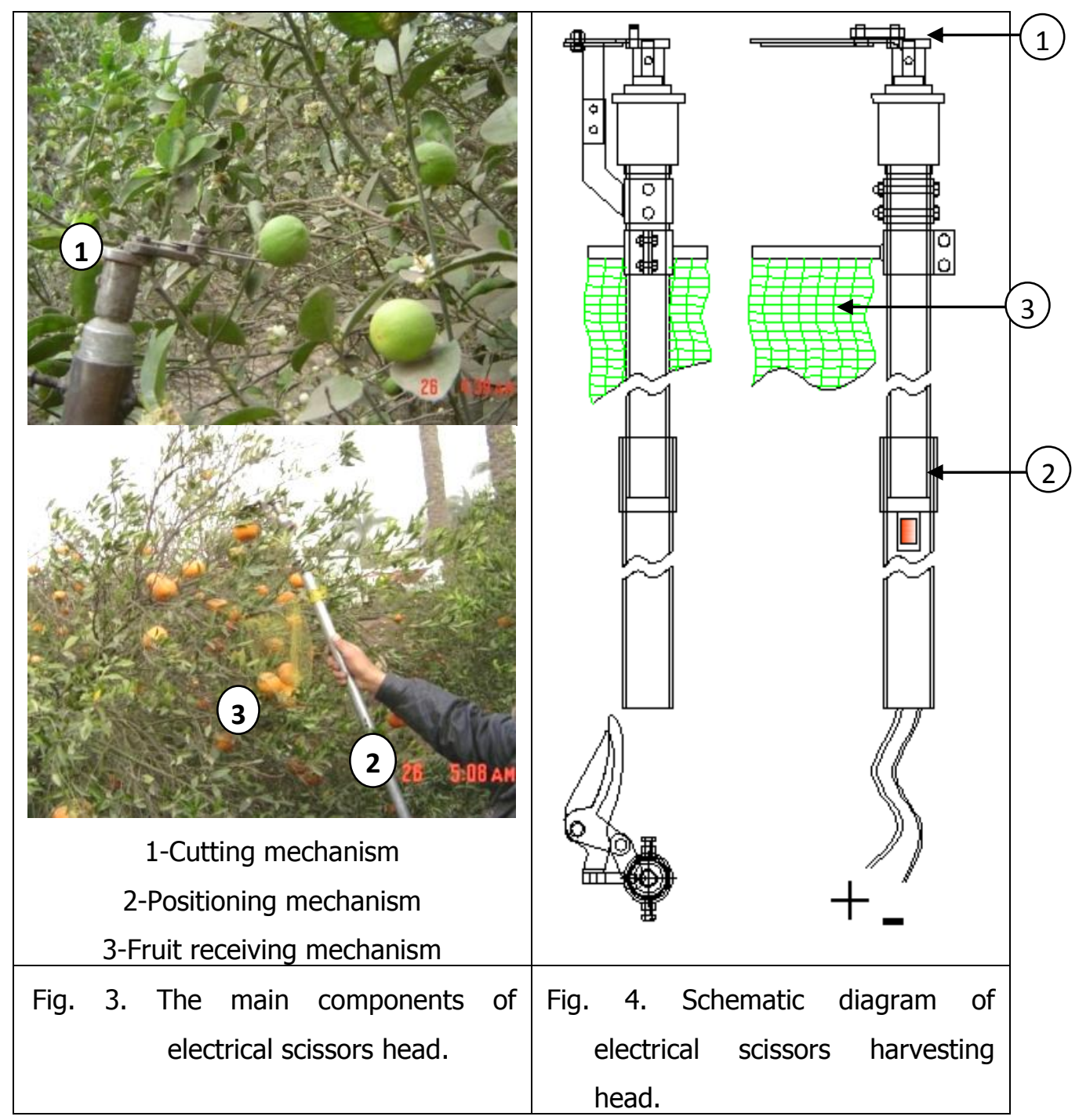




\section{2-Positioning and housing mechanism}

It consists of telescopic carrier which can change its height according the fruit height on the tree (3-5m) for adjusting cutting angle of selected fruits to be harvested. In addition to, carry out the cutting mechanism at the upper end of it.

3 -Fruit receiving and collecting mechanism it consists of :

a) Fruit receiving screw tube is fixed in a suitable position on the housing mechanism to receive the detached fruit and transported it to the collecting basket .

b) Fruit collecting basket which attached at the lower end of the telescopic receiving tube to collect a citrus mass of detached fruits. This basket is equipped with two wheel to make it easy during moving between trees in field and emptying it form fruits.

\section{1- 3 Traditional harvesting methods}

The traditional harvesting method used by farmer for harvesting Washingtonia, Valencia, and Mandarin fruits is the picking by hand with assistance lifting platforms such as ladder. However, the traditional harvesting method used by farmer for harvesting the Lemon fruits is shaking the tree or biting the tree bunches to drop the lemon fruits on the ground then manually collecting.

\section{2- Performance test and evaluation}

The prototype of rotary cone harvesting head was evaluated and tested (Citrus aurantium) using the four types of rotary cone under four different cone rotational speeds, namely 300, 450, 600, and $750 \mathrm{rpm}(1.73,2.54,3.45$, and $4.31 \mathrm{~m} / \mathrm{s}$, respectively) for harvesting Washingtonia and Valencia orange fruit varieties. However, The prototype of the electrical scissors harvesting head was evaluated and tested using five different skill labors for harvesting citrus fruit of Washingtonia and Valencia orange, Mandarin (citrus nobilis -King Mandarin), and lemon (citrus aurantifolia - Lemon). The field experiment and test evaluation of the rotary cone picking and electrical scissors harvesting heads were carried out during two citrus harvesting seasons of 2007 and 2008 at the attached citrus farm of Mansoura university.

\section{3- Measurements}

\section{3-1 Citrus tree characteristics}

The citrus tree canopy characteristics that effect on the performance of designed harvesting tools were investigated and measured such as, tree height, mean diameter of tree canopy, height of the $1^{\text {st }}$ branch, tree spacing, layers of fruit distribution and its percentage on the tree canopy. 


\section{3-2 Citrus fruit and its twig properties}

The important physical and mechanical properties of citrus under investigation, that affect on the performance of the designed harvesting tools, such as fruit mass ,fruit major (d1), minor (d2) and mean diameters (fruit dimensions), fruit twig length/diameter and the cutting force by the torsional torque action on the fruit twig was measured according to the method described by El Khawaga (1999). The liner dimensions were measured by a digital caliper to an accuracy of $0.01 \mathrm{~mm}$. However, the fruit mass was measured by electronic digital balance to an accuracy of $0.001 \mathrm{~g}$. Three random samples of fruits (each sample 20 fruits) were taken from four different citrus fruit varieties under study for measuring physical and mechanical properties of citrus fruits and its twig. Twig diameter was measured with a digital caliper. directly after the detachment of the fruit.

\section{3-3 Total harvesting time and productivity}

The total harvesting time and labor productivity were used as an indicator to evaluate the performance of the designed harvesting head prototypes in comparison with traditional harvesting methods. The total harvesting time was recorded for full working day to estimate the average labor productivity (ton/h) using different harvesting tools under study. The total harvesting time includes selecting, detecting and detaching fruit to be harvested, collecting or gathering detached fruits in the basket and emptying it. In addition to, the time required for moving harvesting tools between trees inside the field.

\section{3-4 Quality of picked citrus fruits}

The quality of harvested fruits (Washingtonia and Valencia) using rotary cone harvesting head was estimated by taken five boxes randomly from each harvesting method. The fruits in each box were sorted into four grades, namely, Grade I: with calyx / extra fancy, Grade II: without calyx, Grade III: with twig and Grade IV: damaged (fruit with cracks), according to the practices of El-Wady Company for

Exporting Agricultural Products. The number of citrus fruits for each grade was recorded and the percentage of all grades was then estimated. However, the quality of harvested fruits using electrical scissors head was evaluated by sorted the picked fruits to four grades according to the length of fruit twig namely, Grade I, includes fruits with twig less than $0.5 \mathrm{~cm}$, Grade II, includes fruits with twig of $0.5-2 \mathrm{~cm}$, Grade III, includes fruits with twig more than $2 \mathrm{~cm}$ and the Grade IV, includes the percentage of damaged fruits (which dropped out receiving tube). 


\section{3-5 Harvesting cost estimation}

The harvesting cost (LE/h and LE/ton) was estimated during harvesting Washingtonia, Valencia, Mandarin and Lemon fruits using rotary cone and electrical scissors heads as a mechanical methods comparing with traditional harvesting methods. The following assumption bases were taken into consideration during estimation of harvesting cost: labor wage ( $4 \mathrm{LE} / \mathrm{h})$, collecting labor wage ( $3 \mathrm{LE} / \mathrm{h})$, rotary cone or electrical scissors heads cost (1100 LE), harvesting head life (3 years with 200 yearly working hours), one labor for mechanical method and two labors for traditional method (one for picking and other for collecting fruits).

\section{RESULTS AND DISCUSSION}

\section{1- Citrus tree canopy characteristics}

The average value of the tree height for all citrus varieties of Washingtonia, Valencia, Mandarin and Lemon trees were found to be 4.1, 4.6, 4.4 and $4.02 \mathrm{~m}$, respectively. However, the average value of tree canopy diameter was $5.0 \mathrm{~m}$ for all citrus varieties under study. The $1^{\text {st }}$ branch on the tree start at height of $0.5-0.6 \mathrm{~m}$ from the ground surface with 4-5 main branches for each tree. The average value of citrus trees spacing are $4 \times 4 \mathrm{~m}$ as shown in Fig.(5). The maximum fruit distribution percentages on citrus tree were found on the outer circumference of the citrus canopy, while the average value of fruits distribution percentages on different layers of the tree height are shown in Fig.(6).

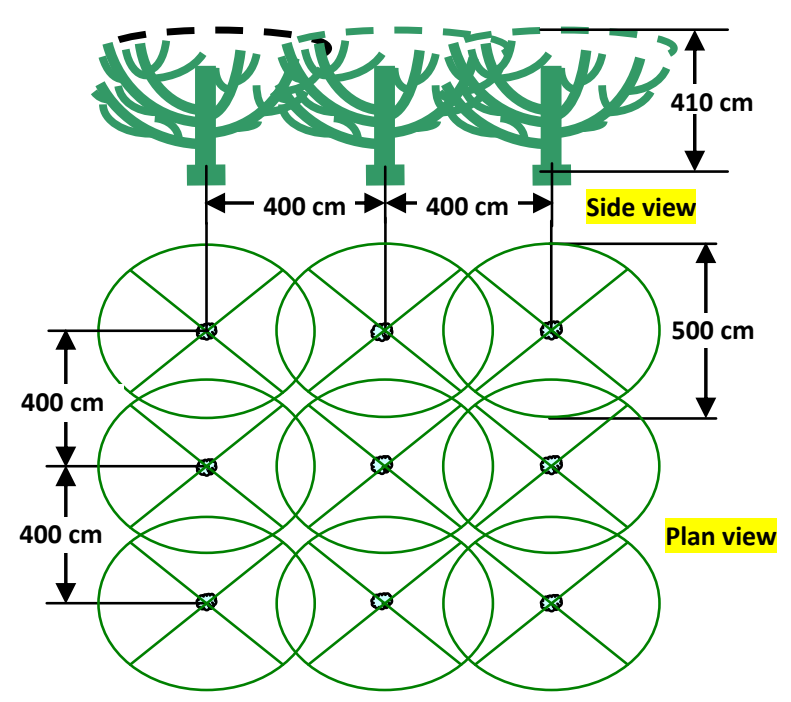

Fig. 5. Average spacing between citrus trees and the tree dimensions. 


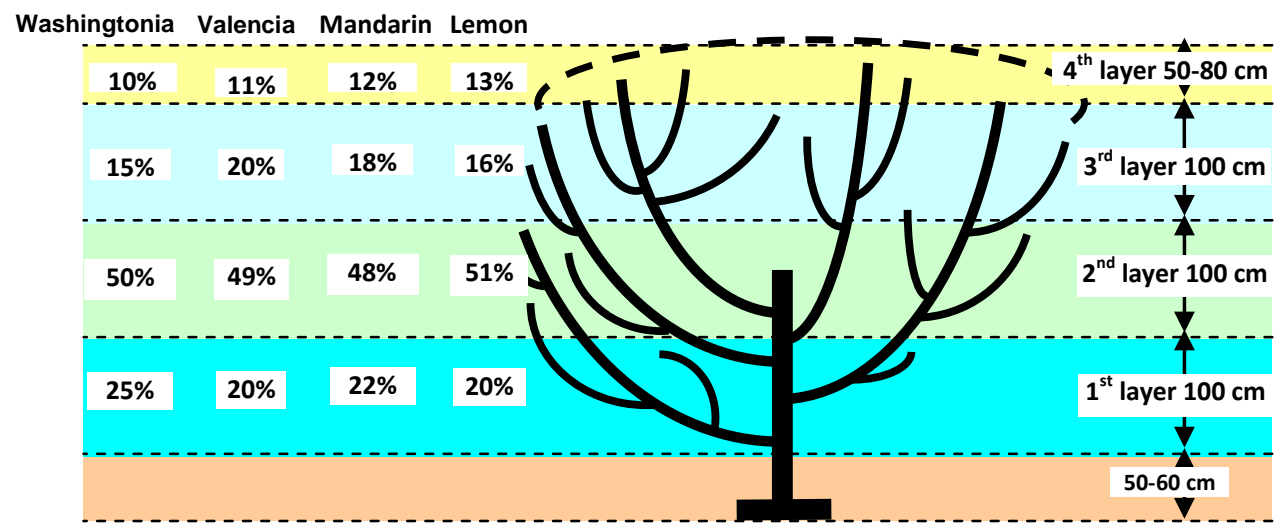

Fig. 6. Distribution percentage of fruit layers on the citrus trees canopy.

\section{2-Physical properties of fruit and its twig}

The average values and standard deviation (SD) of measured physical and mechanical properties of citrus fruits varieties under study (Washingtonia and Valencia orange, Mandarin and Lemon fruits) were analyzed and summarized in Table (1). From this Table, it could be concluded that there are differences between the average values of measured physical properties for all citrus fruits under study. The obtained results indicated that the average values of the length, diameter mass, Twig diameter and Cutting force of twig of the Washingtonia orange variety fruits were found to be higher than obtained for the Valencia, Mandarin and Lemon varieties fruits.

Table 1. Physical properties of some citrus fruits and its twig.

\begin{tabular}{|c|c|c|c|c|c|c|c|c|}
\hline \multirow{2}{*}{ Measurements } & \multicolumn{2}{|c|}{ Washingtonia orange } & \multicolumn{2}{|c|}{ Valencia orange } & \multicolumn{2}{c|}{ Mandarin } & \multicolumn{2}{c|}{ Lemon } \\
\cline { 2 - 10 } & Average & SD & Average & SD & Average & SD & Average & SD \\
\hline D1 (mm) & $\mathbf{6 7 . 0}$ & 0.56 & $\mathbf{6 3 . 3}$ & 0.31 & $\mathbf{5 5 . 1}$ & 0.31 & $\mathbf{3 6 . 3}$ & 0.28 \\
\hline D2 (mm) & $\mathbf{6 6 . 2}$ & 0.54 & $\mathbf{7 1 . 6}$ & 0.36 & $\mathbf{4 2 . 4}$ & 0.25 & $\mathbf{3 5 . 6}$ & 0.14 \\
\hline Mass (g) & $\mathbf{1 7 3 . 4}$ & 35.8 & $\mathbf{1 4 4 . 4}$ & 21.6 & $\mathbf{7 0 . 9}$ & 7.09 & $\mathbf{2 8 . 1}$ & 2.53 \\
\hline Twig diameter ( mm) & $\mathbf{3 . 4 0}$ & 0.63 & $\mathbf{2 . 7 9}$ & 0.24 & $\mathbf{2 . 6 1}$ & 0.39 & $\mathbf{1 . 8 3}$ & 0.71 \\
\hline Cutting force of twig (N) & $\mathbf{8 3 . 7 8}$ & 0.62 & $\mathbf{6 4 . 2 6}$ & 1.11 & $\mathbf{6 1 . 3 2}$ & 2.17 & $\mathbf{5 9 . 8 1}$ & 2.31 \\
\hline
\end{tabular}

\section{3- Performance evaluation of the rotary harvesting cone head}

\section{3-1- Rotary cone head productivity}

The labor productivity (ton/h) using different rotary cone head types were evaluated under four different cone rotational speed of 300, 450, 600 and $750 \mathrm{rpm}$ for harvesting of Washingtonia and Valencia orange fruits. The obtained results are illustrated in Fig. (7). From this Figure it could be seen that increasing the cone rotary 
speed up $600 \mathrm{rpm}$ for harvesting Washingtonia and Valencia orange fruits gave a decrease in detachment time, consequently increase in cone productivity using any given of cone types. However, increasing cone rotational speed than $600 \mathrm{rpm}$ for picking Washingtonia and Valencia orange fruits gave a decrease in cone productivity. The main reasons behind these results may be due to escape fruit from harvesting cone by increasing its speed, which results in an increment in the number of trying times and the lost time to detect and detach the fruit from the tree, consequently, increasing the total fruit harvesting time and decreasing the labor productivity. However, providing the harvesting cone with upper edge and internal rubber layer affect positively on the cone productivity as shown in Fig. (7).

Using harvesting cone type IV (metal cone provided with rubber inner surface and without upper edge) at cone rotary speed of $600 \mathrm{rpm}$ gave the maximum labor productivity of 0.208 and 0.154 ton/h for harvesting Washingtonia and Valencia orange fruits, respectively. These results may be due to increase the effect of fruit detachment action by increase the friction of coefficient between cone inner surface and fruit surface which decrease the detachment time and increase the productivity. While, using harvesting cone type II (metal cone providing with upper edge) gave the lowest labor productivity values of 0.119 and $0.091 \mathrm{ton} / \mathrm{h}$ at rotating speed of 300 rpm during harvesting Washingtonia and Valencia orange fruits, respectively. These results may be due to some obstacles happen from the upper edge during detecting and detaching the fruit from the tree, in addition to the decreasing effect of the friction coefficient between cone inner surface and fruit surface.
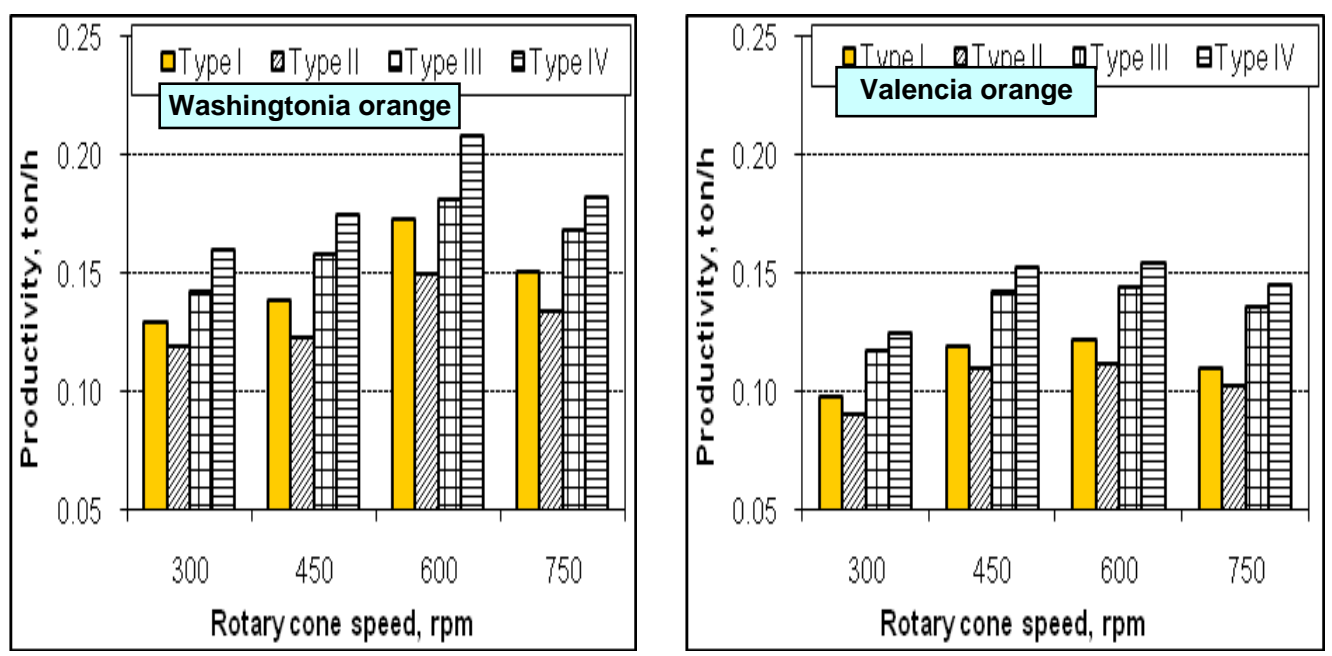

Fig. 7. Effect of using cone harvesting head on the labor productivity. 
The obtained labor productivity values were 0.111 and 0.084 ton/h using traditional methods for harvesting Washingtonia and Valencia orange fruits, respectively. These values were increased by a range of $43.58-86.85 \%$ for harvesting Washingtonia orange fruits and by a range of $49.04-84.15 \%$ for harvesting Valencia orange fruits when using cone type IV of harvesting head at the range of $300-750 \mathrm{rpm}$ cone rotating speed.

\section{3-2 Fruit quality}

The effect of using different types of rotary cone picking head and its rotating speeds on the picked fruit quality were measured, analyzed and illustrated in Fig. (8). From these results it could be concluded that the fruit quality items were highly affected by the cone types and its rotating speed, especially the percentage of damaged fruits (the percentage of dropped fruit out the fruit receiving tube and basket) which causes a decrease fruit quality and decrease its salable yield has a major impact on the total picking cost .

The percentage values of fruits without calyx (Grade I), with twig (Grade III) and damaged fruit (Grade IV) were increased by increasing rotary cone speed during harvesting Washingtonia and Valencia orange fruits for all cone types under study. However, the percentage values of fruits with calyx (Grade I) were decreased by increasing rotary cone speed during harvesting Washingtonia and Valencia orange fruits for all cone types under study. These results may be due to high torsional action occurred with high rotary speed. 


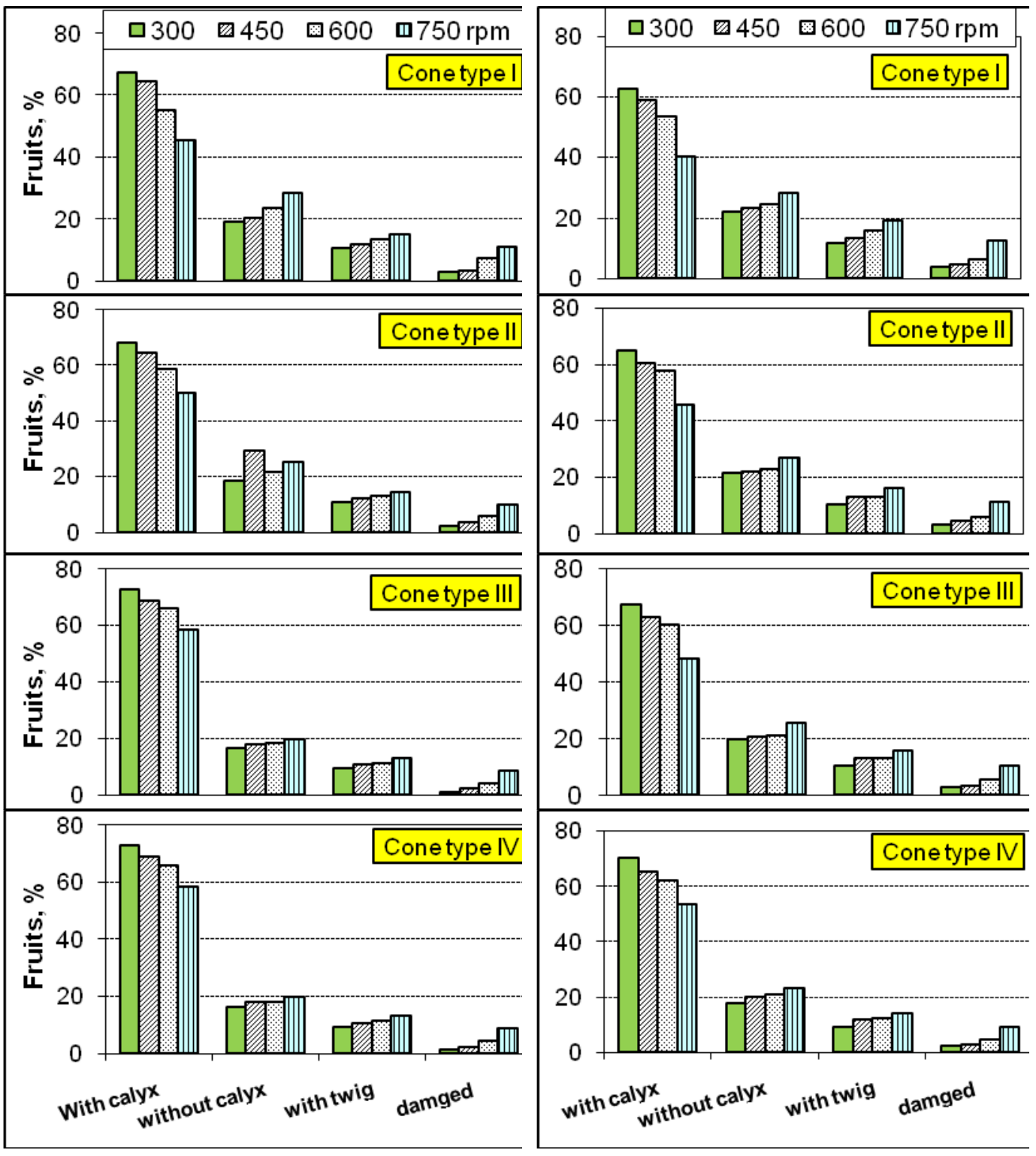

Fig. 8. Effect of using cone harvesting head on the harvesting quality of Washingtonia (left) and Valencia (right) orange fruits.

The optimum fruit quality (the highest percentage of fruit with calyx-Grade I and lowest percentage of fruit Grades III and IV) was obtained by using harvesting cone type IV (metal covered by rubber layer on the inner surface and with upper edge) in comparison with other harvesting cone types under study. The percentage values of the fruit with calyx of $65.96 \%$ (Grade I-extra fancy), fruits without calyxGrade II $18.26 \%$, fruits with twig-Grade III $11.46 \%$ and damaged fruits-Grade IV $4.31 \%$ were obtained when using harvesting cone type IV at rotary cone speed of 600rpm during harvesting Washingtonia orange fruits. However, the corresponding values obtained during harvesting Valencia orange fruits were $62.39 \%$ (Grade I), 
$20.79 \%$ (Grade II), $12.16 \%$ (Grade III) and $4.66 \%$ (Grade IV) at 600 rotary cone speed.

\section{4- Performance evaluation of the electrical scissors picking head}

\section{4-1- Electrical scissors productivity}

The prototype of electrical scissors harvesting head was evaluated using five different skill labors for harvesting Washingtonia, Valencia, Mandarin and Lemon citrus fruits. The average harvesting productivity for different skill labors comparing with traditional harvesting methods were illustrated in Fig. (9). The highest productivity $(0.153$ ton/ $h$ ) was obtained using electrical scissors comparing with 0.084 ton/h using traditional harvesting method for harvesting Valencia orange fruits, followed by 0.129 using electrical scissors comparing with 0.111 ton/h using traditional method for harvesting Washingtonia orange fruits. However the productivity was decreased to $0.084 \mathrm{ton} / \mathrm{h}$ and $0.016 \mathrm{ton} / \mathrm{h}$ using the electrical scissors comparing with 0.053 and 0.013 ton/h using traditional harvesting method for harvesting Mandarin and Lemon fruits respectively. In spite of decreasing the productivity of harvesting lemon fruits by using electrical scissors but it consider a good indicator for the productivity comparing with traditional harvesting method of lemon because the difficulty of the hand harvesting of lemon fruits due to a lot of barbs on the main and sub branches of lemon tree, which affect directly on the labor hands and obstacles him during harvesting operation.

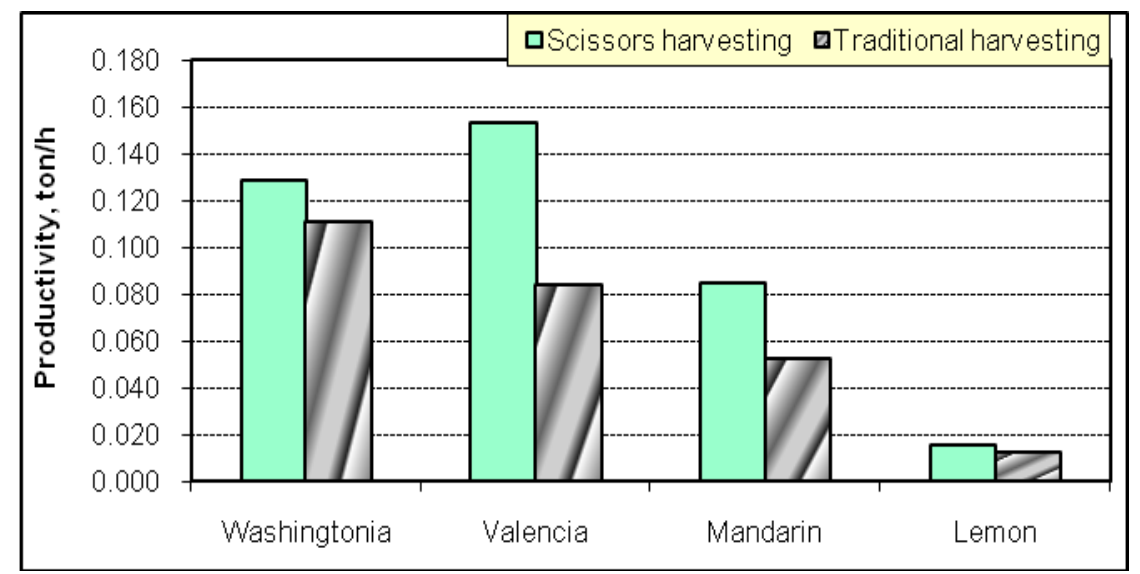

Fig. 9. Effect of using electrical harvesting scissors on the labor productivity of citrus fruits.

\section{4-2 Fruit quality}

The effect of using electrical scissors head on the harvested citrus fruits qualities were measured, and calculated for each citrus varieties. The obtained percentage of each grade were illustrated in Fig. (10). This figure cleared that the 
percentage of grade I ( $<0.5 \mathrm{~cm}$ twig length) was found to be the superior percentage compared with other two grades for all harvested fruits under study. It were $43.35,51.15,51.78$ and $53.00 \%$ for harvesting Washingtonia and Valencia orange, Mandarin and Lemon fruits, respectively. However, the damaged fruits percentages of $6.71,4.55,3.55$ and $1.97 \%$ were found to be the lowest values for harvesting Washingtonia and Valencia orange, Mandarin and Lemon fruits, respectively.

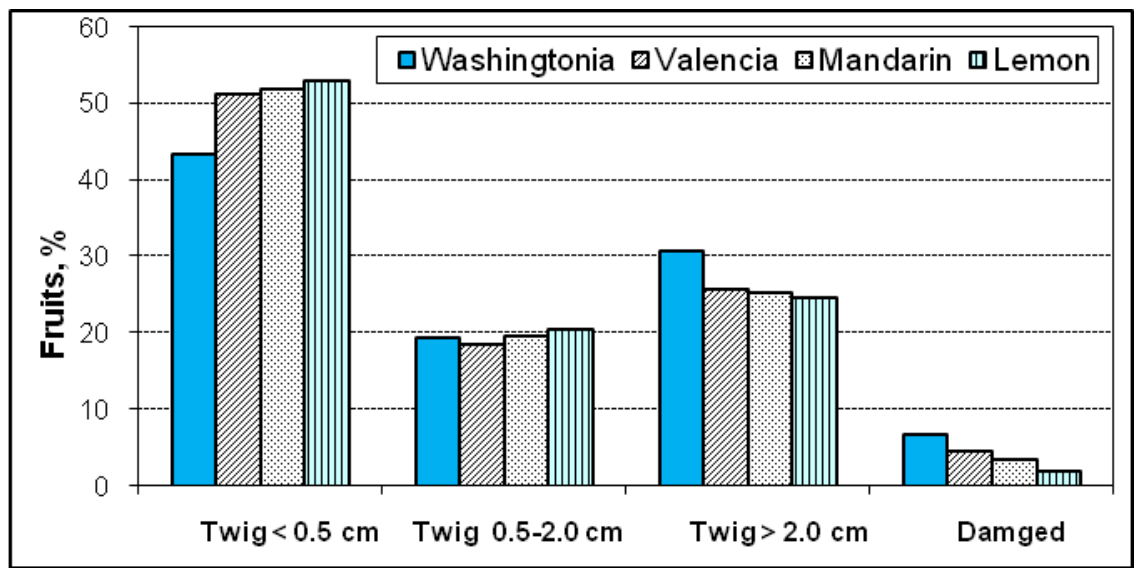

Fig. 10. Effect of using electrical harvesting scissors on the fruit quality.

\section{4- Harvesting cost}

The average values of estimated harvesting cost (LE/h) were found to be 6 and $7 \mathrm{LE} / \mathrm{h}$ for harvesting citrus fruits, using mechanical and traditional methods, respectively. However, the average values of harvesting cost were 39.43 and 49.68 LE/ton using rotary cone head or 46.65 and $39.22 \mathrm{LE} /$ ton using electrical scissors head in comparison with 62.92 and $83.46 \mathrm{LE} /$ ton using traditional methods for harvesting Washingtonia and Valencia orange fruits, respectively. Using the designed mechanical harvesting heads under study saving the harvesting cost by about 25.85 $59.58 \%$ for harvesting Washingtonia orange fruits and by about $53.00-67.99 \%$ for harvesting Valencia orange fruits comparing with traditional citrus harvesting methods.

\section{CONCLUSION}

- Using harvesting rotary cone type IV (metal cone provided with rubber inner surface and without upper edge) at cone rotary speed of $600 \mathrm{rpm}$ increased the labor productivity from 0.111 and 0.084 ton/h using traditional harvesting method to 0.208 and 0.154 ton/h for harvesting Washingtonia and Valencia orange fruits, respectively and maintain the optimum fruit quality by increasing the percentage 
of fruit with calyx-Grade I (65.96-73.01\%) and decreasing the percentage of damaged fruit Grade IV (1.20-4.31\%).

- Using electrical scissors head increased the labor productivity from $0.111,0.084$, 0.053 and 0.013 ton/h using traditional harvesting method to $0.153,0.129,0.084$ and 0.016 ton/h with maintain the higher percentages of grade I $(<0.5 \mathrm{~cm}$ twig length) of $43.35,51.15,51.78$ and $53.00 \%$ and the lower damaged fruit percentages of $6.71,4.55,3.55$ and $1.97 \%$ for harvesting Washingtonia and Valencia orange, Mandarin and Lemon fruits, respectively.

- Using mechanical citrus harvesting methods saving the harvesting cost by about 25.85 - 59.58\% for harvesting Washingtonia orange fruits and by about 53.00 $67.99 \%$ for harvesting Valencia orange fruits comparing with traditional citrus harvesting methods.

\section{REFERENCES}

1. Abou EI-Kheir, M. M. 1993. Mechanical arm for lime-fruit picking. Misr J. Ag. Eng., 10 (3): 385- 401.

2. Abou Elmagd A. E., A. S. Hamam, M. A. El-Saadany and S. E. EI-Khawaga. 2002. Design of a cone-end detacher for orange picking. Misr J. Ag. Eng. 19(2): 191507.

3. Ben-Tal Y. 1983. Horticulture aspects of mechanical fruit harvesting . Proc. Intl . Symp. On Fruit, Nut and Veg. Harvesting Mechanization. Amer. Soc. Agr. Eng. Sp-5: 372-375.

4. Brown, G.K. 2002. Mechanical harvesting systems for the Florida citrus juice industry. Paper No: 021108, ASAE Annual International Meeting/CIGR . (pp. 11)

5. Burks, T., F. Villegas, M. Hannan, S. Flood, B. Sivaramam, V. Subramanian and J. Sikes. 2005. Engineering and horticultural aspects of robotic fruit harvesting : Opportunities and Constraints. Hortitechnology, 15 (1), pp. 79-87.

6. Chinchuluun, R, W.S. Lee and R. Ehsani. 2009. Machine Vision System for Determining Citrus Count and Size on A Canopy Shake and Catch Harvester. Applied Engineering in Agriculture Vol. 25(4): 451-458. American society of Agricultural and Biological Engineers ISSN 0883-8542.

7. El-Khwaga S. E. 1999. Developing of a harvesting machine for some fruit crops. Ph.D. Thesis. Agric. Eng. Dept., Agric. Fac., EI-Mansoura Univ.

8. El-Wady Company for Exporting Agricultural Products. 1999. Personal communications. 
9. Futch, S.H., and F.M. Roka. 2005. Continuous canopy shake mechanical harvesting systems. EDIS. UF/IFAS. Gainesville, Fla.

10. Futch, S. H., J. D. Whitney, J. K. Burns and F. M. Roka. 2004. Harvesting from manual to mechanical. The Citrus Industry. Vol. February, 2004, pp. 21-22.

11. Grand d'Esnon, A. G. Rabatal, R. Pellene, A. Journeau, and M. J. Aldon. 1987. A self-propelled robot to pick apples. ASAE Paper No 87-1037.

12. Herrell R. C., D. Adist, R. Hoffman, R. Munilla, D.C. Slaughter and T. Pool. 1990. The Florida robotic grove lab. Transaction of the ASAE. 33 (3): 213-221.

13. Horticultural Institute Brochure. 2003. No. 850.

14. O'brien. M., B. F. Cargill and R. B. Fridly. 1986. Principles and practices for harvesting fruits and nuts. AVI Publi. Co. INC, Westport. Connecticut.

15. Sanders, K. F. 2005. Orange harvesting systems review. Bio-systems Engineering, Power and Machinery, 90 (2), 115-125.

16. Seamount D. T. and K. W. Opitz. 1973a. The Auto-Picker: A two-man positioning machine. Citrograph, 59(1), 23-27

17. Sumner H. R. 1978. Mechanical removal of fruit from citrus trees. Proc. Inst. Soc. Citriculture. 2 : 407-412.

18. Whitney J. D., T. A. Wheaton, W. S. Castle and D. P. H. Tucker. 1996. Orange grove factors affect manual harvesting Rates. Transactions of the ASAE, 39(2), 399-405. 


\section{وتقييم نماذج آلية لحصاد ثمار الموالح}

عاطف سليمان حمام ، محمود السيد العراقى يوسف فرج شاروبيم طاهر رشاد عويس

$$
\text { معهز بحوث العندسة الزراعية - مركز البحوث الزراعية - الدقى - الجبزة . }
$$

تعتبرعملية قطف أو جمع ثمار الفاكهة من أهم العمليات التى تجرى على أشجار الفاكهة

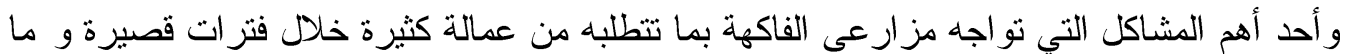
يترتب عليه من انخفاض جودة الثمار وزيادة فى مقدار تكلفة الإنتاج. ومن ثم فكان الهدف الأساسي

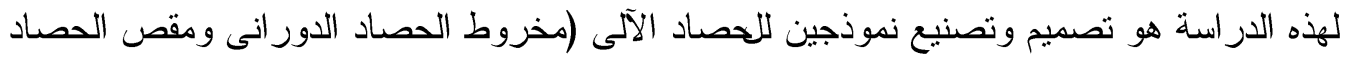

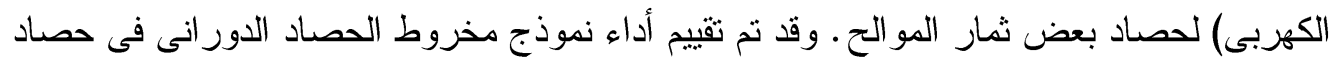

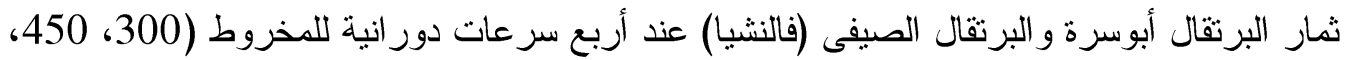

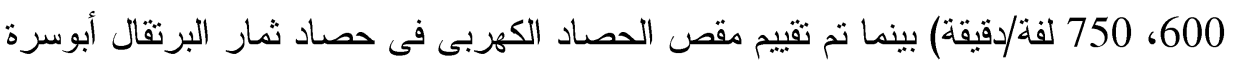
و الصيفى (فالنشيا) و اليوسفى و الليمون باستخدام 5عمال مختلفة المهارة وقد كانت أهم نتائج هذه

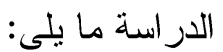

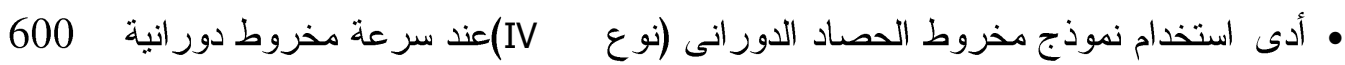
لفة/دقيقة إلى زيادة إنتاجية العامل من 0.1110 .084 ، 0.00 طن/ساعة باستخدام الطرق اليدوية

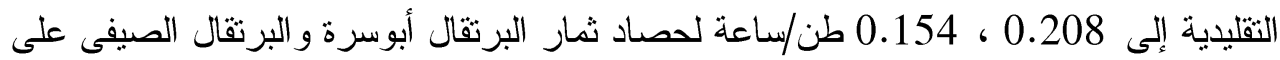
التو الى مع المحافظة على الجودة العالية للثمار وذلك بزيادة نسبة ثمار البرتقال الجيدة و الصالحة

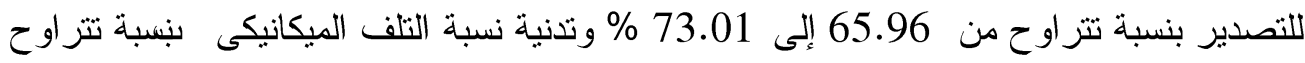
من 1.20 إلى 4.31 \%

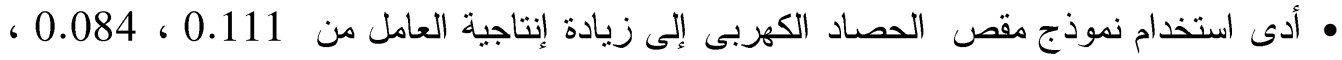

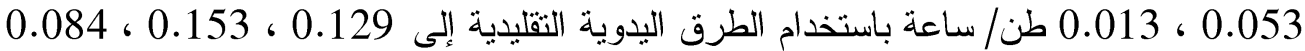

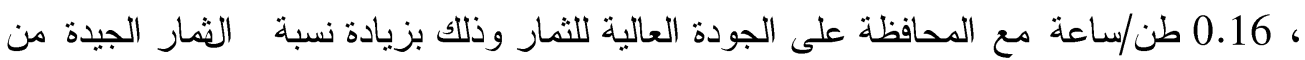

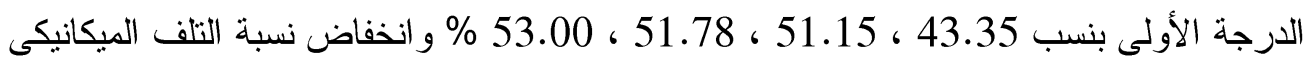
إلى 6.71 ، 4.55 ، 3.55 ، 1.97 \% لحصاد ثمار البرتقال أبوسرة والبرنقال الصيفى و اليوسفى و الليمون على التو الى.

• أدى استخدام نماذج الحصاد الآلية إلى التوفير فى تكاليف عملية الحصاد بنسبة تتز اوح من 25.58 من

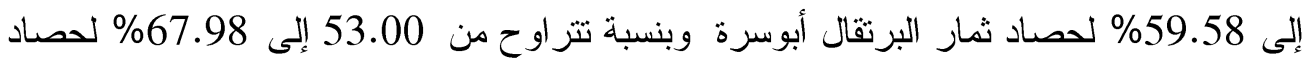
ثمار البرتقال الصيفى (الصى

• يوصى الباحثون بالتصنيع المحلى واستخدام كل من مخروط الحصاد الدور انى ومقص القطف

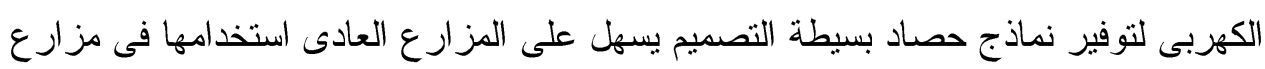

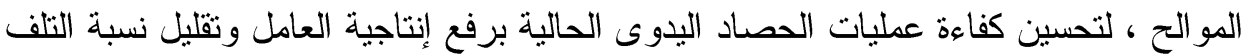

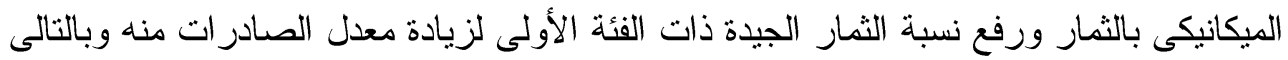

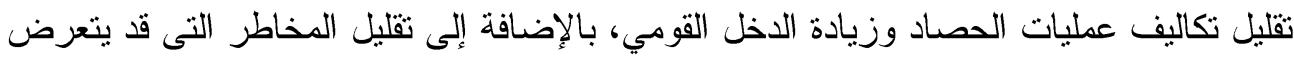

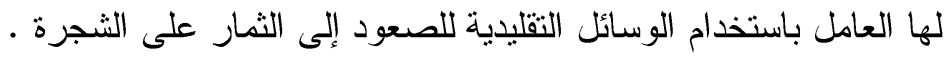

